\title{
EVALUATION OF VIRTUAL SURGICAL PLANNING AND CAD/CAM TECHNIQUES IN TREATMENT OF MANDIBULAR FRACTURES VIA THREE-DIMENSIONAL PATIENT-SPECIFIC TITANIUM PLATES: A CASE SERIES
}

\author{
Mohamed Farid Shehab*, Dina Adel Taalab** and Mohammed Atef ${ }^{* * *}$
}

\begin{abstract}
Background: The study aimed to evaluate and assess the clinical stability and efficacy of 3D patient-specific computer-guided titanium plates (3D-PSP) for accurate reduction and fixation of mandibular fractures.

Methods: Ten patients were selected suffering from mandibular body/ para-symphyseal fractures, treated with 3D-PSP. Clinical evaluation included; Patient satisfaction, Pain, Occlusion and Occlusal Bite force. Radiographic parameter evaluated was fracture gap distance. The operating time was also measured during the surgery.
\end{abstract}

Results: The occlusal bite forces showed significant increase at 3 months $(p \leq 0.05)$ follow up. The fracture gap distance revealed a mean of $0.64 \pm 0.40 \mathrm{~mm}$ at one week and $0.30 \pm 0.38 \mathrm{~mm}$ at 3 months. The operating time showed a mean of 8:58 $\pm 02: 39$ mins:secs.

Conclusions: 3D patient specific plates showed accurate reduction and stability of mandibular fractures with decreased operative time. Superior adaptation on bony surfaces offered increased biting forces and decreased risk of plate fracture and design flexibility avoided mental nerve damage.

KEYWORDS: Computer-guided surgery, Mandibular fractures, Patient-specific plates, Titanium plates, CAD/CAM, Three dimensional plates, Virtual Surgical planning.

\section{INTRODUCTION}

Mandibular fractures are among the common facial injuries, Mandibular body fractures constitute about $41.5 \%$ of mandibular fractures ${ }^{(1-3)}$. The use of double miniplates following Champy's principles (4) for treatment of mandibular body fractures

\footnotetext{
* Associate Professor, Oral \& Maxillofacial Surgery Department, Faculty of Dentistry, Cairo University.

** Oral \& Maxillofacial Surgery Department, Faculty of Dentistry, Cairo University.

*** Lecturer, Oral \& Maxillofacial Surgery Department, Faculty of Dentistry, Cairo University.
} 
is considered to be the gold standard treatment modality. However, the disadvantages of the conventional miniplate system in mandibular body fractures includes the precise adaptation required between the plate/bone interface, the requirement of an additional second plate at the superior border to counteract the tension forces ${ }^{(5)}$.

With the introduction of three-dimensional (3D) plating system in 1995 by Farmand ${ }^{(6)}$, several authors have concluded that the 3D plating system offers more favorable biomechanical properties than the conventional miniplates in terms of stability and strain resistance in different regions of the mandible ${ }^{(7-9)}$. Nevertheless Jain et al $201{ }^{(10)}$ and Mittal et al $2016^{(11)}$ found that even though 3D plates were found to be better than 2D miniplates in respect of operating time, cost and facilitating the surgery. With the evolution of the Virtual Surgical Planning, Rapid prototyping (RP) techniques, and computeraided manufacturing/computer numerical control (CAM/CNC) processes, the utilization of these methods to produce patient specific implants/plates (PSP) provided great possibilities for better fracture reduction and fixation ${ }^{(12)(13) \cdot(14)(15)}$.

In the light of this, our study was conducted aiming to evaluate and assess the clinical stability and efficacy of Three-dimensional patient specific computer-guided titanium plates for accurate reduction and fixation of mandibular body and/or parasymphyseal fractures.

\section{MATERIALS AND METHODS}

This study was carried out on ten patients suffering from isolated, non-comminuted mandibular body and/or parasymphyseal fractures without any other associated maxillofacial fractures. Patients were selected from the outpatient clinic at the department of Oral and Maxillofacial Surgery, faculty of dentistry, Cairo University. All patients who fulfilled the selection criteria filled and signed a consent for participation in the study. The study was approved by the ethical committee of the Faculty of dentistry, Cairo University.

All patients were examined clinically by inspection and palpation both extraorally and intraorally to detect any associated maxillofacial fractures. Preoperative occlusion was evaluated to determine occlusal discrepancies before the surgery. Paresthesia or anesthesia of areas supplied by the mental nerve was detected and recorded if present using 'Two point discrimination test (TPD)' (16). Preliminary Panoramic radiograph was done to assess the fracture line and then Cone-beam CT (CBCT) or computerized tomography $(\mathrm{CT})$ were performed for all patients.

\section{Preoperative 3D Patient Specific Plate designing and manufacturing:}

The patients DICOM (Digital communication) files from the CBCT/CT were imported into the Mimics ${ }^{\circledR}$ medical 19.0 software (Materialise $\AA$ Interactive Medical Image Control System). Image segmentation was used to highlight regions of interest and 3D reconstruction of the mandible. Virtual reduction of the fracture was then done by transferring the reconstructed virtual 3D digital model of the mandible to another software (3-matic $\AA$ medical 11.0, Materialise $\left.{ }^{\circledR}\right)$ where the fractured segments are being virtually reduced guided by the occlusion with the upper teeth and the position of the condyles in the glenoid fossa.

A plate was designed specifically for each patient using sketching tools and transformed into a 3D structure rectangular in shape with 6 arms and 8 screw holes Fig. (1). We started with a plate thickness of $1.5 \mathrm{~mm}$ as a pilot study at the first case and then the thickness was adjusted to $1.2 \mathrm{~mm}$. Screw holes were created with a diameter of 1.8 $\mathrm{mm}$ and a clearance of $0.1 \mathrm{~mm}$ to allow for seating of the screw.

Finishing and smoothening of the final plate structure was then done, and the design was transformed to an STL file which was sent to the 


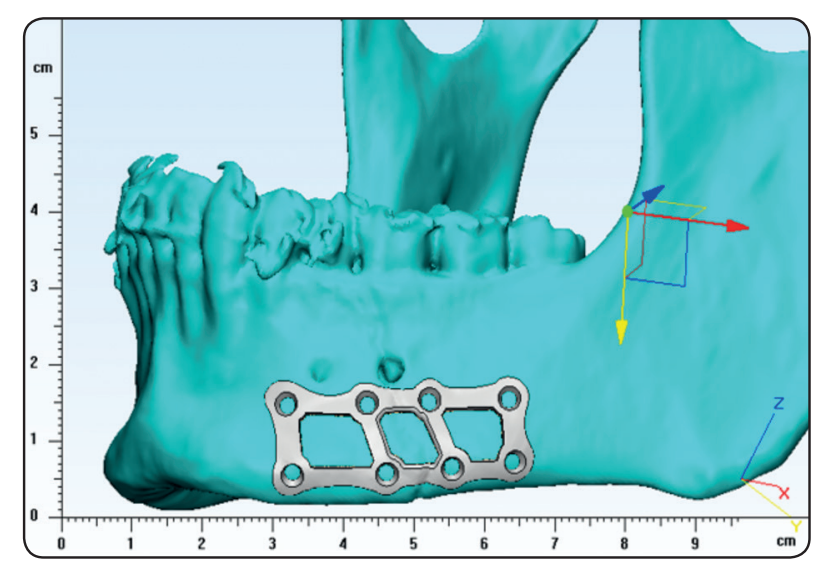

Fig. (1): A 3D view of the mandible showing the 3DPSP designed and adapted on the virtually reduced fractured segments in case 5 .

engineer for milling. A CNC programming software for manufacturing by $\mathrm{CAD} / \mathrm{CAM}$ milling machine (Millstar Jiuh-Yeh LMV 40 2S). The 3D patientspecific plates (3DPSP) were milled from grade 3 pure titanium blocks. The finished 3DPSP were then cleansed and packed for sterilization using the standard protocols before the surgery as shown in Fig. (2).

\section{Surgical procedure:}

Full laboratory investigations and medical consultation were requested to reveal patients' fitness to undergo surgery under general anesthesia. Patients were scrubbed and draped in a standard surgical fashion, the fracture was approached

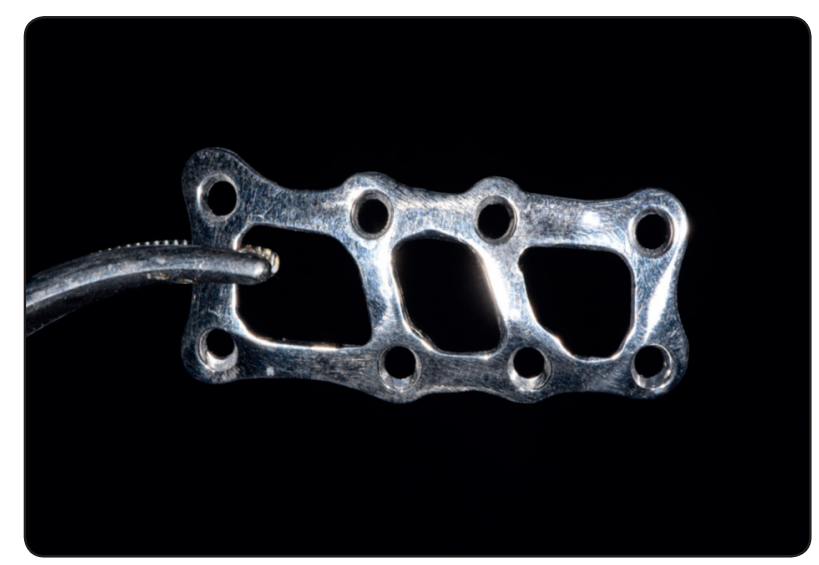

Fig. (2): A Photograph showing the final 3D printed PSP before placement. through an intraoral vestibular incision leaving a healthy cuff of tissue along the gingiva to facilitate ease of closure and avoid dehiscence. The mental nerve was then identified and dissected to ease its movement and to prevent possible avulsion from the foramen by retractors. Any hematoma or fibrous tissue present between the fractured segments was removed by curettage of the bony edges, then the segments were manipulated and reduced, and the occlusion was reestablished. The mandible was placed into maxillomandibular fixation and the reduced fracture was stabilized.

After maximum intercuspation was achieved with maxillomandibular fixation, the 3DPSP was placed to fit on the bony surface of the mandible as preoperative planning and was fixed using eight screws of varying lengths Figs. (3). Intra-oral suturing was done in a standard fashion using Vicryl 4/0 and the maxillomandibular fixation was released.

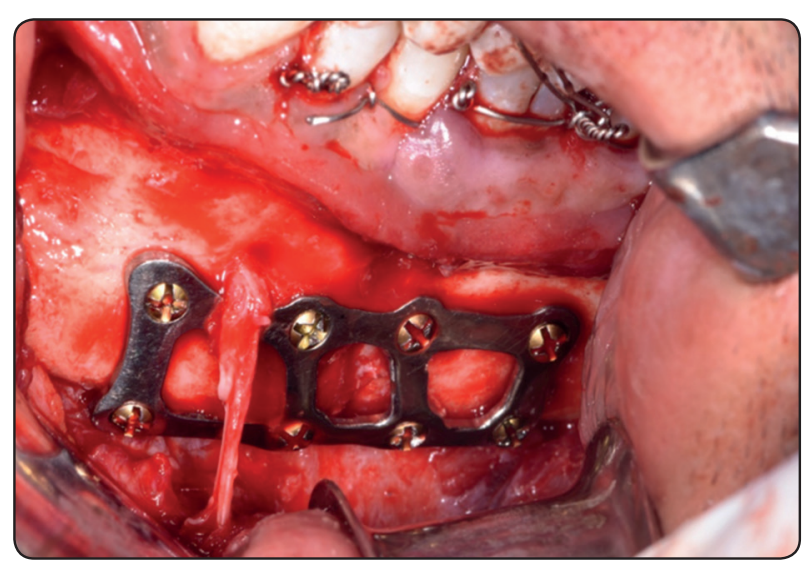

Fig. (3): A photograph showing reduction and fixation of the fracture with the patient specific plate with 8 screws.

\section{Postoperative care and follow up}

All patients received the prescribed medications after surgery including antibiotics, analgesics, anti-edematous and mouthwash. All patients were followed up and assessed clinically after three days, one week, two weeks, one and three months postoperatively regarding different parameters such as wound healing, degree of mouth opening, extent of postoperative edema and infection. All patients 
were assessed radiographically by $\mathrm{CBCT} / \mathrm{CT}$ at one week and three months follow up visits. Outcome measurements were recorded at two intervals at one week and 3 months postoperatively to assess the following parameters: patient satisfaction, pain, occlusal bite force, accuracy of reduction, occlusion discrepancy and the operating time.

Patient satisfaction was measured on a visual analogue scale (VAS) ${ }^{(17)}$ of $0-10$, with zero being unsatisfied and 10 being satisfied. Pain was also measured by (VAS) ${ }^{(17)}$ of $0-10$. The degree of occlusal derangement was graded as: Mild: slight derangement of occlusion and no need for intervention, Moderate: the occlusion was deranged, and the function was affected and need correction by non-surgical means (elastics or teeth grinding) and Severe: gross occlusal derangement with functional disability that needs reoperation.

The degree/accuracy of reduction was measured radiographically by $\mathrm{CBCT/CT}$ at one week and three months follow up visits. The fracture gap distance was measured in millimeters between the fractured segments at five different points, the 5 points were indicated on the panoramic view (after panoramic curve was first created on mimics), and then on an axial view. The gap distance was measured at each indicated point twice (one at the buccal cortex and the second at the lingual cortex) using intra and inter-observer reliability ${ }^{(18)(19)}$ and the average of each point and all summed five points were calculated and recorded.

Occlusal Bite force was measured through the follow up visits (1 week and 3 months) by using a portable occlusal force gauge called OCCLUSAL FORCE-METER (GM10, Nagano Keiki, Higashimagome, Ohta-ku, Tokyo, Japan) Fig. (4) ${ }^{(20)}$. The biting force was calculated in Newtons $(\mathrm{N})$ and displayed digitally. The measurements of the bite force were taken and recorded at the incisor region, normal side and fractured side. Finally, the operating time was recorded using a stopwatch, from the start of the plate application on the mandible till fixation of the plate by screws.

Categorical data were presented as frequencies (n) and percentages (\%) and was analyzed using McNemar-Bowker Test which was used for intragroup comparisons. Quantitative data were explored for normality using KolmogorovSmirnov and Shapiro-Wilk tests. Parametric data were analyzed using paired t-test for intragroup comparisons. Nonparametric data were analyzed using Wilcoxon signed-rank test for intragroup comparisons. The significance level was set at $\mathrm{P} \leq$ 0.05 for all tests. Statistical analysis was performed with IBM® ${ }^{\circledR}$ SPSS ${ }^{\circledR}$ (SPSS Inc., IBM Corporation, NY, USA) Statistics Version 25 for Windows.

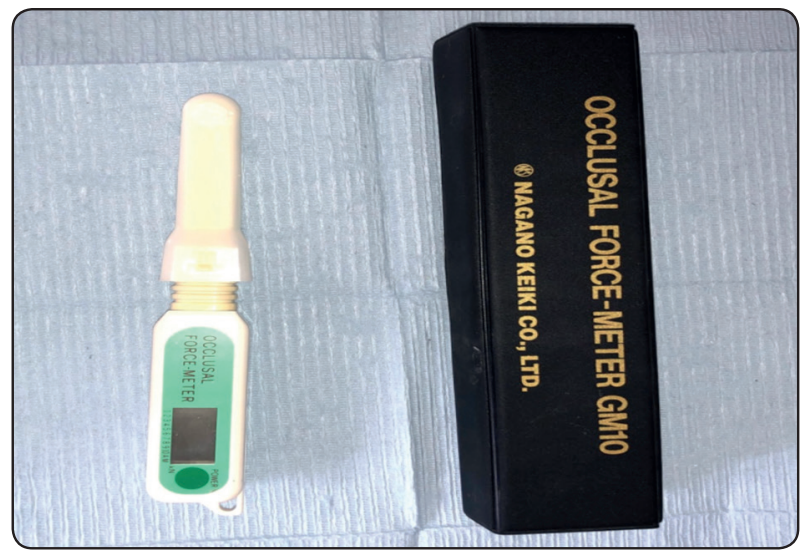

Fig. (4): A photograph showing the occlusal force-meter GM10 associated with a disposable plastic cap and storage case.

\section{RESULTS}

All patients showed uneventful healing with no signs of wound dehiscence, infection or mental nerve injury postoperatively during the whole follow up period. Results were analyzed and tabulated as shown in Table (1). Ten patients were included in this study, nine patients $(90 \%)$ were males and one female $(10 \%)$ with a mean age of $(27.40 \pm 7.14)$. The most prevalent cause of fracture was road traffic accidents (RTA) in five patients $(50 \%)$ followed 
by criminal assault in four patients (40\%) while only one patient $(10 \%)$ was fractured due to sports accident.

Patient satisfaction and pain scores are shown in table (1). Correction of occlusion was evaluated by the degree of occlusal derangement after the surgery, two patients have shown mild occlusal derangement which did not need any intervention. After 3 months postoperatively all patients have shown normal occlusion.
CBCT was taken at one and three months postoperatively Fig. (5). The fracture gap distance measurements showed a significant decrease after 3 months follow up with a significant level as $(\mathrm{p}<0.001)$ shown in table (1). The values of occlusal bite force at the fractured side, normal side and incisor regions are shown in table (1). The operating time was measured from the start of the adaptation of the plate to the mandible until the end of drilling of the last screw showing a mean of 8:58 $\pm 02: 39$ mins:secs.

TABLE (1): Showing the mean and standard deviation of the bite force at the fracture site, the normal side and incisal in Newtons at one week and 3 months postoperatively and their p-values. The mean and standard deviation of fracture gap distance in $\mathrm{mm}$, patient satisfaction and pain at one week and 3 months postoperatively and their p-values. The percentage and frequency of normal occlusion, mild, moderate or severe occlusal derangement at one week and 3 months postoperatively and their p-values and the mean and standard deviation of the operating time in minutes: seconds at the time of the surgery.

\begin{tabular}{|c|c|c|c|c|c|c|c|c|c|c|}
\hline & \multicolumn{3}{|c|}{$\begin{array}{c}\text { Bite force }(\mathrm{N}) \\
(\text { Mean } \pm \mathrm{SD})\end{array}$} & \multirow{2}{*}{$\begin{array}{c}\text { Fracture } \\
\text { gap distance } \\
(\mathrm{mm}) \\
(\mathrm{Mean} \pm \mathrm{SD})\end{array}$} & \multicolumn{3}{|c|}{ Occlusal derangement } & \multirow{2}{*}{$\begin{array}{c}\text { Patient } \\
\text { satisfaction } \\
(\mathrm{Mean} \pm \mathrm{SD})\end{array}$} & \multirow{2}{*}{$\begin{array}{c}\text { Pain } \\
(\text { Mean } \pm \text { SD })\end{array}$} & \multirow{2}{*}{$\begin{array}{c}\text { Operating } \\
\text { time } \\
\text { (mm:ss) } \\
\text { (Mean } \pm \text { SD) }\end{array}$} \\
\hline & $\begin{array}{c}\text { Fracture } \\
\text { site }\end{array}$ & $\begin{array}{c}\text { Normal } \\
\text { side }\end{array}$ & Incisal & & & $\%$ & (n) & & & \\
\hline \multirow[t]{4}{*}{ Baseline } & \multirow{4}{*}{$\begin{array}{c}117.50 \pm \\
39.73\end{array}$} & \multirow{4}{*}{$\begin{array}{c}221.30 \pm \\
74.92\end{array}$} & \multirow{4}{*}{$\begin{array}{c}49.00 \pm \\
35.62\end{array}$} & \multirow[t]{4}{*}{$0.64 \pm 0.40$} & Normal & $80.0 \%$ & 8 & \multirow[t]{4}{*}{$7.80 \pm 1.40$} & \multirow[t]{4}{*}{$4.40 \pm 0.84$} & \multirow[t]{9}{*}{$08: 58 \pm 02: 39$} \\
\hline & & & & & Mild & $20.0 \%$ & 2 & & & \\
\hline & & & & & Moderate & $0 \%$ & 0 & & & \\
\hline & & & & & Severe & $0 \%$ & 0 & & & \\
\hline \multirow{4}{*}{$\begin{array}{c}3 \\
\text { Months }\end{array}$} & \multirow{4}{*}{$\begin{array}{c}430.70 \pm \\
57.51\end{array}$} & \multirow{4}{*}{$\begin{array}{c}585.60 \pm \\
134.13\end{array}$} & \multirow{4}{*}{$\begin{array}{c}119.00 \pm \\
75.80\end{array}$} & \multirow[t]{4}{*}{$0.30 \pm 0.38$} & Normal & $100.0 \%$ & 10 & \multirow[t]{4}{*}{$9.20 \pm 0.79$} & \multirow[t]{4}{*}{$0.40 \pm 0.84$} & \\
\hline & & & & & Mild & $0 \%$ & 0 & & & \\
\hline & & & & & Moderate & $0 \%$ & 0 & & & \\
\hline & & & & & Severe & $0 \%$ & 0 & & & \\
\hline P-value & $<0.001 *$ & $<0.001 *$ & $<0.001 *$ & $<0.001 *$ & \multicolumn{3}{|c|}{$0.500 \mathrm{~ns}$} & $0.010 *$ & $0.004 *$ & \\
\hline
\end{tabular}

*; significant $(p \leq 0.05) n s ;$ non-significant $(p>0.05)$

(n) ; frequency 


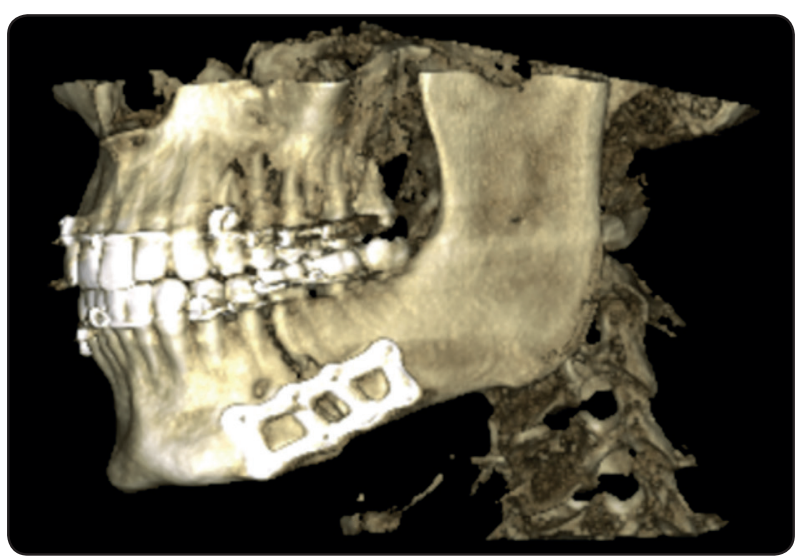

Fig. (5): A 3D view from CBCT for case 5 at one month postoperatively showing proper reduction of the fractured segments and adaptation of the plate.

\section{DISCUSSION}

The study was aiming to assess the influence of designing and manufacturing a 3D titanium miniplate according to patient's specific needs on the accuracy of reduction and stability of mandibular body fractures.

Several authors have concluded that the 3D plating system offers more favorable biomechanical properties than the conventional miniplates ${ }^{(8)}(7-9)$. However, they were unfavorable for cases where fracture line was oblique and in close proximity to mental foramen, where they were difficult to adapt and more chances for inadvertent injury to the mental nerve and tooth-root damage ${ }^{(13)}$. The flexibility in the 3D PSP designing regarding plate thickness, contouring of the plate to conform to the anatomy of the mandible avoiding the location of the mental nerve and aligning with the direction of the fracture line is believed to be a major advantage. Moreover, selecting the sizes and angles of the screw holes in accordance with individual requirements will decrease the incidence of tooth-root damage.

It has been hypothesized that repeated intraoperative manual plate bending, which sometimes occurs when using trial-and-error adaptation of a plate, can increase the risk of metal fatigue and plate fracture, however, biomechanical tests and more clinical trials are required to provide further evidence for this hypothesis ${ }^{(21)}$. The 3DPSP offered a unique solution for this dilemma where the plate is accurately adapted over the bony surface according to the preplanned position taking the contour of the mandible.

The occlusal bite force measurements significantly increased after three months follow up, our results were consistent with Ellis et al ${ }^{(22)}$ who found that bite forces in the acute postoperative period are much lower than bite forces recorded later in the postoperative period or in the non-operated population. The reason for reduced bite forces after surgery can be attributed to the protective neuromuscular mechanisms pre-sent throughout the body ${ }^{(23-25)}$. Feller et al ${ }^{(26)}$ concluded that masticatory load exceeding $200 \mathrm{~N}$ on the plates occurs only 3 months after osteosynthesis at that time the fracture is largely consolidated. The 3DPSP showed a value of $(430.70 \pm 57.51 \mathrm{~N})$ at the fractured side after 3 months thus regaining normal function and biting forces to standard levels.

The 3D feature of the patient specific plate is a suspected factor for the higher bite force results due to the geometrically closed quadrangular or rectangular plate fixed to provide stability in the three dimensions of space ${ }^{(7,27)}$ eliminating the requirement of an additional second plate at the superior border to counteract the tension forces. Our results are supported by the findings of George et al ${ }^{(28)}$, where bite force measurements were used to compare stability and rigidity of standard threedimensional (3D) titanium plates and conventional titanium miniplates for mandibular anterior fractures treatment, the maximum voluntary bite force measurement postoperatively was found to be greater in patients with 3D titanium plates than those with titanium miniplates, it was concluded that $3 \mathrm{D}$ titanium plates are better in efficacy compared to standard titanium miniplates. 
Precise adaptation required between the conventional plate/bone interface is essential because stability can only be achieved when the screw head compresses the plate to the bone, which may unfortunately cause further adjacent bone resorption and consequently screw loosening and treatment failure $^{(29)}$, a disadvantage that was resolved by the superior adaptation of the 3DPSP over the bony surface of the mandible providing increased rigidity and fixation to the fractured segments.

In the current study, evaluating the accuracy of reduction was done by measuring the fracture gap width on the first week and 3 months postoperative $\mathrm{CBCT} / \mathrm{CT}$ which was produced by the same machine for all patients. The current study revealed a mean of $0.64 \pm 0.40 \mathrm{~mm}$ at one-week interval and a mean of $0.30 \pm 0.38 \mathrm{~mm}$ at 3 months follow up interval. Evaluation of the fracture gap distance, in the treatment of mandibular fractures using 3DPSP was not found in literature. However these results were comparable with Malhotra et al ${ }^{(7)}$, comparing between conventional 3D plates and conventional miniplates in the management of mandibular fractures.

The operating time was measured from the start of the plate application to the mandible until the end of drilling of the last screw, in our study the operating time showed a mean of 8:58 $\pm 02: 39$ mins:secs. According to Bhatt et al, it has been shown that the healing process, possible complications and the degree of facial swelling in the treatment of mandibular fractures can be influenced by duration of operating time which is often related to surgical difficulties in repositioning the osteosynthesis ${ }^{(30)}$.

\section{CONCLUSIONS}

3D patient specific plates offered accurate reduction of mandibular fractures, superior adaptation over the bony surfaces with decreased risk of plate fatigue and fracture and provided high stability and increased biting forces. The design flexibility favours it's uses with oblique fractures, prevented mental nerve and root injury. Finally, the 3DPSP shortened the operating time thus reducing the postoperative complications.

\section{REFERENCES}

1. Morrow BT, Samson TD, Schubert W, et al. Evidencebased medicine: Mandible fractures. Plast Reconstr Surg. 2014;134(6):1381-90.

2. Goodday RH. Management of fractures of the mandibular body and symphysis. Oral Maxillofac Surg Clin North Am. 2013; 25(4):601-16.

3. Braasch DC, Abubaker AO. Management of mandibular angle fracture. Oral Maxillofac Surg Clin North Am. 2013;25(4):591-600.

4. Champy M. Mandibular Osteosynthesis by Miniature Screwed Plates Via a Buccal Approach. J max-fac Surg 6 1978, 14-21.

5. Hu W, Agrawal M, Thadani S et al. Comparative evaluation of a single 2.0-mm AO locking reconstruction plate with conventional miniplate osteosynthesis for treatment of linear non-comminuted fractures of symphysis and parasymphsis region of the mandible. J Stomatol Oral Maxillofac Surg. 2019;120(1):11-5.

6. Farmand M. Three dimensional plate fixation of fractures and osteotomies. Facial Plast Surg Clin North Am 1995, 3(1):39-56.

7. Malhotra K, Sharma A, Giraddi G et al. Versatility of Titanium 3D Plate in Comparison with Conventional Titanium Miniplate Fixation for the Management of Mandibular Fracture. J Maxillofac Oral Surg. 2012; 11(3):284-90.

8. Alkan A, Celebi N, Ozden B et al. Biomechanical comparison of different plating techniques in repair of mandibular angle fractures. Oral Surg Oral Med Oral Pathol Oral Radiol Endod. 2007;104(6):752-6.

9. Farmand M, Dupoirieux L. The value of 3-dimensional plates in maxillofacial surgery. Rev Stomatol Chir Maxillofac. 1992;93(6):353-7.

10. Jain MK, Manjunath KS, Bhagwan BK et al. Comparison of 3-dimensional and standard miniplate fixation in the management of mandibular fractures. J Oral Maxillofac Surg. 2010;68(7):1568-72. 
11. Mittal Y, Varghese KG, Mohan S et al . A Comparative Study of 3-Dimensional Titanium Versus 2-Dimensional Titanium Miniplates for Open Reduction and Fixation of Mandibular Parasymphysis Fracture. J Maxillofac Oral Surg. 2016;15(1):93-8.

12. Dean D, Min KJ, Bond A. Computer aided design of large-format prefabricated cranial plates. J Craniofac Surg. 2003; 14(6):819-32.

13. Singare S, Dichen L, Bingheng L, et al. Design and fabrication of custom mandible titanium tray based on rapid prototyping. Med Eng Phys. 2004;26(8):671-6.

14. Levine JP, Patel A, Saadeh PB, et al. Computer-aided design and manufacturing in craniomaxillofacial surgery: the new state of the art. J Craniofac Surg. 2012;23(1):288-93.

15. Yang WF, Choi WS, Leung YY, et al. Three-dimensional printing of patient-specific surgical plates in head and neck reconstruction: A prospective pilot study. Oral Oncol. 2018;78:31-6.

16. Cashin AG, McAuley JH. Measuring two-point discrimination threshold with a caliper. J Physiother. 2017; 63(3):186.

17. Wewers ME, Lowe NK. A critical review of visual analogue scales in the measurement of clinical phenomena. Res Nurs Health. 1990;13(4):227-36.

18. Downing SM. Reliability: on the reproducibility of assessment data. Med Educ. 2004;38(9):1006-12.

19. JL Fleiss. Reliability of measurement in the design and analysis of clinical experiments.: Wiley online library; 1986.

20. Kumar ST, Saraf S, Devi SP. Evaluation of bite force after open reduction and internal fixation using microplates. $\mathrm{J}$ Dent (Tehran). 2013;10(5):466-77.

21. Salgueiro MI, Stevens MR. Experience with the use of prebent plates for the reconstruction of mandibular defects. Craniomaxillofac Trauma Reconstr. 2010;3(4):201-8.
22. W Schilli, HG Luhr. Rigid internal fixation by means of compression plates. Oral and maxillofacial traumatology Quintessence, Chicago,1982 pp 308-370.

23. H Pistner, P Kukiz .Bite forces after orthodontic pretreatment, corrective osteotomy and mandibular fractures Dtsch Zahnärzl Z 1998 : 53: 528-534.

24. Sonnenburg $M$, Voelker $H$. The resilience of the fractured lower jaw in depends on the treatment method. Dtsch Z Mund Kiefer GesichtsChir 1982: 6: 409-413.

25. Gerlach KL, Pape H-D, Nussbaum P. Elastic measurements after osteosynthesis of mandibular fractures. Dtsch Z Mund Kiefer GesichtsChir 1984: 8:363-366.

26. Feller KU, Richter G, Schneider M, et al. Combination of microplate and miniplate for osteosynthesis of mandibular fractures: an experimental study. Int J Oral Maxillofac Surg. 2002;31(1):78-83.

27. Xue AS, Koshy JC, Wolfswinkel EM, et al. A Prospective Study of Strut versus Miniplate for Fractures of Mandibular Angle. Craniomaxillofac Trauma Reconstr. 2013;6(3): 191-6.

28. George D. A Comparative Study Between Titanium Mini Plates And 3 Dimensional Titanium Plates With Locking Screws Using Bite Force Evaluation for Management Of Anterior Mandibular Fractures. Journal of Scientific Dentistry, 2016, 6(2)

29. Haug RH, Street CC, Goltz M. Does plate adaptation affect stability? A biomechanical comparison of locking and nonlocking plates. J Oral Maxillofac Surg. 2002; 60(11): 1319-26.

30. Bhatt K, Roychoudhury A, Bhutia O, et al. Equivalence randomized controlled trial of bioresorbable versus titanium miniplates in treatment of mandibular fracture: a pilot study. J Oral Maxillofac Surg. 2010;68(8):1842-8. 